\title{
PERANCANGAN APLIKASI SISTEM INFORMASI PUSKESMAS SEBAGAI SARANA PENDATAAN IBU DAN ANAK BERBASIS MOBILE
}

\author{
Muhammad Bunyamin ${ }^{1}$, Rezki Pratama² \\ 1,2 Fakultas Ilmu Komputer, Universitas Bina Darma, Palembang, Indonesia \\ Email: 151410247@student.binadarma.ac.id ${ }^{1}$, muhammad.bunyamin@ @inadarma.ac.id ${ }^{2}$
}

\begin{abstract}
In the current era of globalization, technological developments are developing very rapidly along with the needs of the wider community. Information system application is one form of technological and information development. Mother and child data processing at Puskesmas Pedamaran, Pedamaran District, Ogan Komering Ilir Regency does not have an information system application, data collection and data processing of mothers and children still use the writing method or manually using mother and child health books, the method used today is still at risk of experiencing data loss or buildup. Then the authors will conduct research with the aim to build and develop information systems data collection of mothers and children, which can help convey information in a mobile and easier to use in its use, using the waterfall method. The results obtained from this study are in the form of an application of information systems for data collection of mothers and children that makes it easier to provide information on maternal and child health and helps the processing of mother and child data at the Puskesmas. With the application of information systems for data collection of mothers and children, it is certainly expected to further facilitate the processing of mother and child data in the Puskesmas Pedamaran.
\end{abstract}

Keywords: Mobile, Data on mother and child, Waterfall

\begin{abstract}
Abstrak
Pada era globalisasi saat ini perkembangan teknologi berkembang sangat pesat seiring dengan kebutuhan masyarakat luas. Aplikasi sistem informasi merupakan salah satu wujud dari perkembangan teknologi dan informasi. Pengolahan data ibu dan anak di Puskesmas Pedamaran Kecamatan Pedamaran Kabupaten Ogan Komering Ilir belum memiliki aplikasi sistem informasi, pendataan dan pengolahan data ibu dan anak masih menggunakan metode penulisan atau secara manual dengan menggunakan buku kesehatan ibu dan anak, metode yang digunakan saat ini masih beresiko mengalami kehilangan atau penumpukan data. Maka penulis akan melakukan penelitian dengan tujuan untuk membangun dan mengembangkan aplikasi sistem informasi pendataan ibu dan anak, yang dapat membantu menyampaikan informasi secara mobile dan lebih mudah digunakan dalam penggunaannya, dengan menggunakan metode waterfall. Hasil yang diperoleh dari penelitian ini adalah berupa aplikasi sistem informasi pendataan ibu dan anak yang mempermudah dalam memberikan informasi kesehatan ibu dan anak serta membantu proses pengolahan data ibu dan anak pada Puskesmas tersebut. Dengan adanya aplikasi sistem informasi pendataan ibu dan anak ini, tentunya diharapkan lebih mempermudah proses pengolahan data ibu dan anak di Puskesmas Pedamaran.
\end{abstract}

Kata Kunci: Mobile, Pendataan ibu dan anak, Waterfall

\section{Pendahuluan}

Sistem infomasi telah menyebar dan berkembang dengan pesat keseluruh sektor kehidupan. Pada dasarnya sistem infomasi merupakan suatu hal yang sangat penting karena dapat memberikan manfaat secara langsung maupun tidak langsung. Sistem infomasi ini sangat penting, hal ini disebabkan karena dapat membantu masyarakat berfikir lebih luas dalam memanfaatkan sistem informasi tersebut. Perkembangan sistem informasi yang begitu pesat tentu saja membawa dampak signifikan terhadap perubahan dalam bidang pengolahan data kesehatan ibu hamil dan anak khususnya pada Puskesmas. 
Puskesmas Pedamaran yang terletak di Jalan. Demsi Husain Nomor. 004 Dusun 5, Desa Pedamaran VI, Kecamatan Pedamaran Kabupaten Ogan Komering Ilir. Pada dasarnya puskesmas Pedamaran melakukan pendataan kesehatan kepada ibu dan anak di Kecamatan Pedamaran untuk memperoleh informasi dan pelayanan kesehatan yang baik.

Pada saat sekarang ini kualitas sarana dan prasarana di Puskesmas Pedamaran sudah sangat baik. akan tetapi hal ini saja belum cukup karena pengolahan data ibu dan anak masih menggunakan proses pengolahan data secara manual dengan mengisi buku kesehatan ibu dan anak, Penginputan data ibu dan anak dengan cara seperti ini belum cukup karena sering terjadi penumpukan data atau kehilangan data pada saat proses penginputan, dan sulit melakukan rekap data tentang kesehatan ibu dan anak, Serta pada penerapannya buku kesehatan ibu dan anak yang diberikan oleh puskesmas sering tertinggal atau hilang dan juga jadwal pemeriksaan yang sering terlewatkan yang menyebabkan pengisian buku kesehatan ibu dan anak mengalami kendala.

Sejalan dengan perkembangan teknologi yang sangat cepat, untuk mengatasi permasalahan tersebut diperlukan suatu cara pengolahan data berupa sistem informasi pengolahan data berbasis mobile yang dapat menunjang dan mempermudah dalam pengolahan data ibu dan anak yang dapat membantu menyampaikan informasi secara mobile dan lebih mudah digunakan dalam penggunaannya.

\section{Metodologi Penelitian}

\subsection{Skema Alur Penelitian}

Metode penelitian yang dipakai penulis dalam penelitian ini adalah metode penelitian deskriptif. Metode deskriptif adalah suatu metode penelitian yang ditujukan untuk menggambarkan fenomenafenomena yang ada, yang berlangsung saat ini atau saat masa lampau(Paramita et al., 2016).

\subsection{Pengumpulan Data}

Salah satu faktor penting dalam pengembangan sistem informasi adalah memahami sistem, mengumpulkan data yang ada dan berbagai permasalahannya. Adapun cara - cara yang dipakai dalam pengumpulan data adalah sebagai berikut:

a. Observasi

Observasi merupakan kegiatan pengambilan data dengan cara datang langsung ketempat objek penelitian, serta meninjau langsung kondisi dilapangan untuk mendapatkan informasi dan data mengenai objek yang diteliti.

b. Wawancara

Wawancara adalah metode pengambilan data secara langsung ke objek penelitian dan melakukan tanya - jawab untuk mendapatkan data dan informasi seputar objek yang diteliti.

c. Dokumentasi (Pencatatan)

Dokumentasi adalah metode pengambilan data dengan cara melakukan pencatatan dari sebuah dokumen secara langsung dari objek yang diteliti.

\subsection{Pengembangan Sistem}

Metode yang digunakan dalam pembangunan perangkat lunak ini adalah model air terjun (waterfall model) atau sering disebut dengan "alur hidup klasik", serta Unified Modeling Language (UML) sebagai alat bantu analisis serta perancangan perangkat lunak. Tahapan utama dari waterfall model langsung mencerminkan aktifitas pengembangan perangkat 


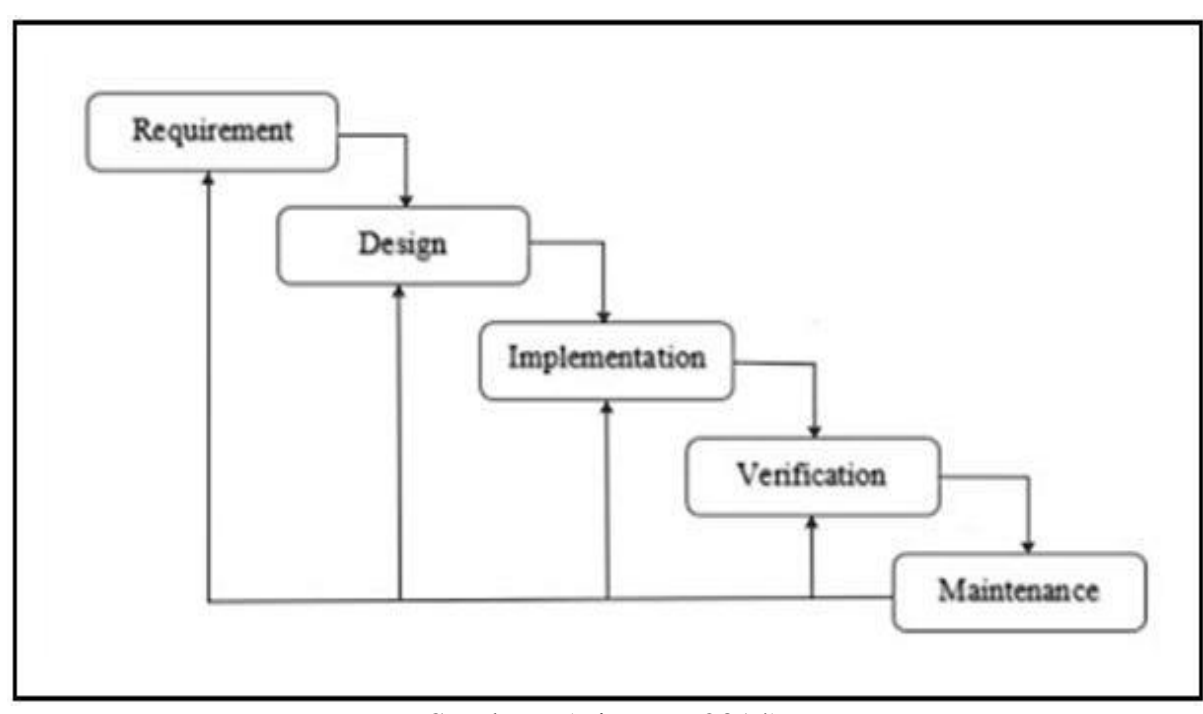

Sumber : (Binanto, 2014).

Gambar 1. Tahapan Metode Waterfall

Untuk mendapatkan gambaran mengenai data yang dibutuhkan dalam pembuatan proposal skripsi ini, metode yang digunakan adalah:

a. Requirement Analysis

Dalam Tahap ini pengembang sistem diperlukan komunikasi yang bertujuan untuk memahami perangkat lunak seperti apa yang dibutuhkan oleh pengguna. Informasi ini biasanya dapat diperoleh melalui wawancara, diskusi atau survei langsung. Informasi dianalisis untuk mendapatkan data yang dibutuhkan oleh pengguna.

b. System Design

Spesifikasi kebutuhan dari tahap sebelumnya akan dipelajari dalam fase ini dan desain sistem disiapkan. Desain Sistem membantu dalam menentukan perangkat keras(hardware) dan arsitektur perangkat lunak dan juga representasi antar muka.

c. Implementation

Pada tahap ini, desain harus ditranslasikan ke dalam program perangkat lunak, yang terintegrasi dalam tahap selanjutnya. Setiap unit dikembangkan dan diuji untuk fungsionalitas yang disebut sebagai unit testing.

\section{d. Testing}

Seluruh unit sistem yang akan dikembangkan dalam tahap implementasi diintegrasikan ke dalam sistem setelah pengujian yang dilakukan masing-masing unit. Setelah integrasi seluruh sistem diuji untuk mengecek setiap kegagalan maupun kesalahan.

e. Maintenace

Tahap akhir dalam model waterfall ini ialah perangkat lunak yang sudah jadi akan dijalankan serta dilakukan proses pemeliharaan. Pemeliharaan termasuk dalam memperbaiki kesalahan yang tidak ditemukan pada langkah-langkah sebelumnya. Perbaikan implementasi unit sistem dan peningkatan jasa sistem sebagai kebutuhan baru.(Rosa A. S and Salahudin, 2018, p. 27)

\section{Hasil dan Pembahasan}

Adapun setelah melakukan serangkaian penelitian maka didapatlah sistem informasi puskesmas kesehatan ibu dan anak yaitu suatu sistem yang pada bagian web dirancang khusus untuk mengelola data ibu hamil, data kesehatan, menyambut persalinan, ibu nifas, bayi baru lahir, rujukan, dan imunisasi, sedangkan pada bagian mobile berfungsi untuk memberikan data informasi kesehatan ibu hamil dan 
notifikasi peringatan kapan harus melakukan pemeriksaan kesehatan dan melakukan vaksin imunisasi kepada anak. Dari hasil penelitian ini diharapkan dapat membantu serta mempermudah pengolahan data dan menyampaikan informasi kepada ibu hamil di Puskesmas Pedamaran.

\subsection{Tampilan Petugas Kesehatan ( Web )}

\section{a. Halaman Login}

Halaman login berfungsi sebagai tempat untuk admin atau petugas kesehatan masuk ke sistem website, agar dapat masuk ke sistem diperlukan email dan password yang sudah didaftarkan lewat aktivasi akun email.

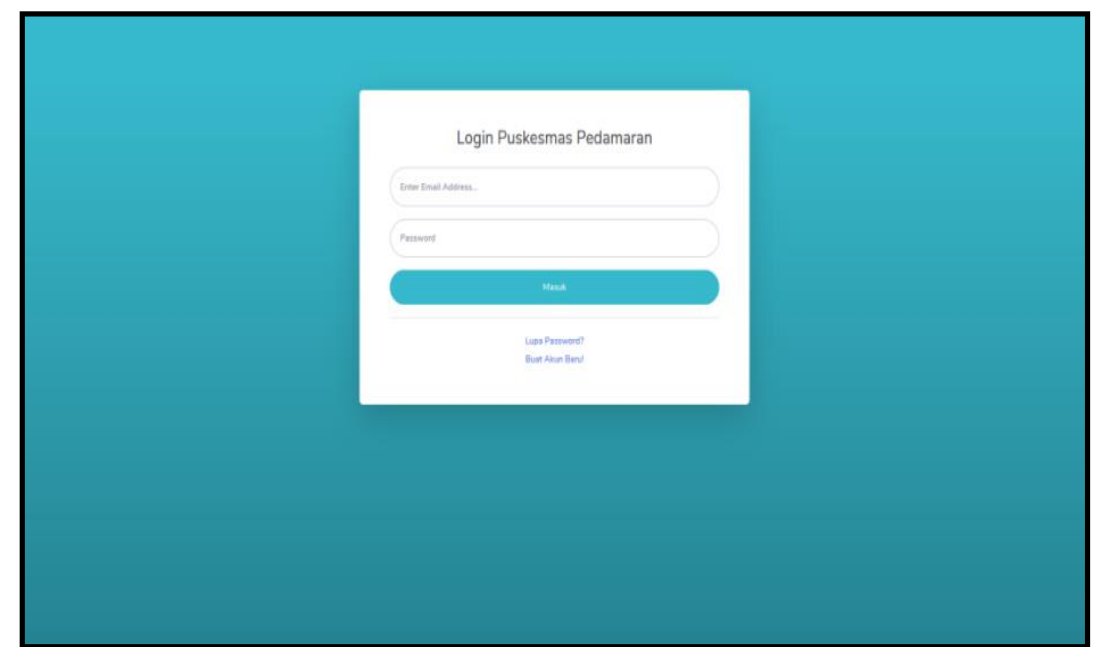

Gambar 2. Halaman Login

b. Halaman Dashboard

Halaman dashboard yang dimana pada halaman ini terdapat menu - menu yang digunakan untuk mengelola data kesehatan ibu dan anak.

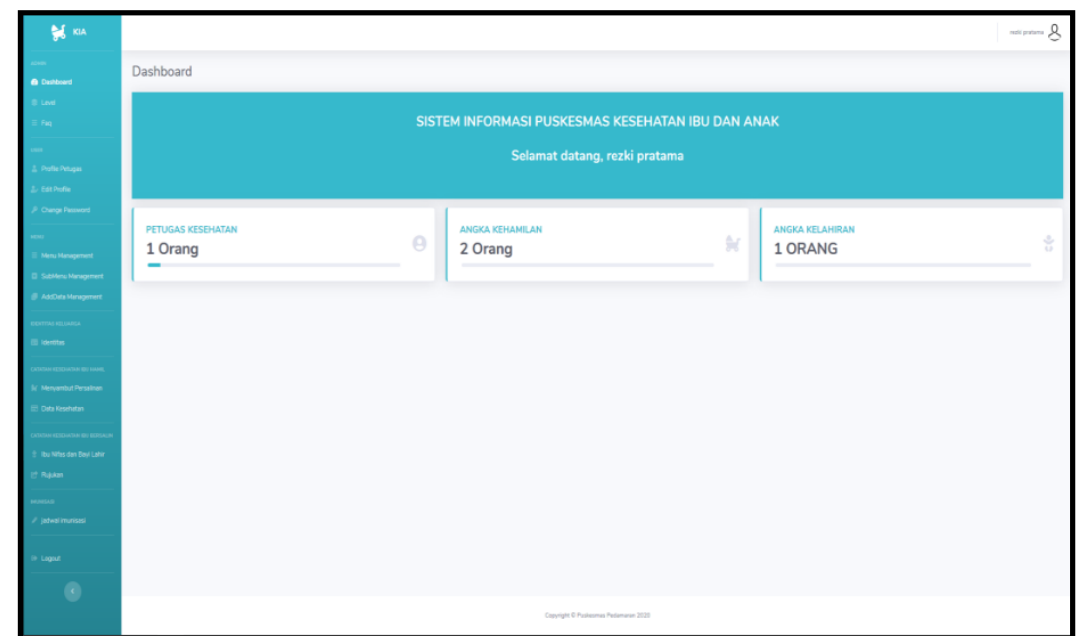

Gambar 3. Halaman Dashboard 
c. Halaman FAQ

Halaman FAQ berfungsi sebagai tempat untuk mengelola data FAQ (Frequently Asked Question) seputar kesehatan ibu hamil dan bayi.

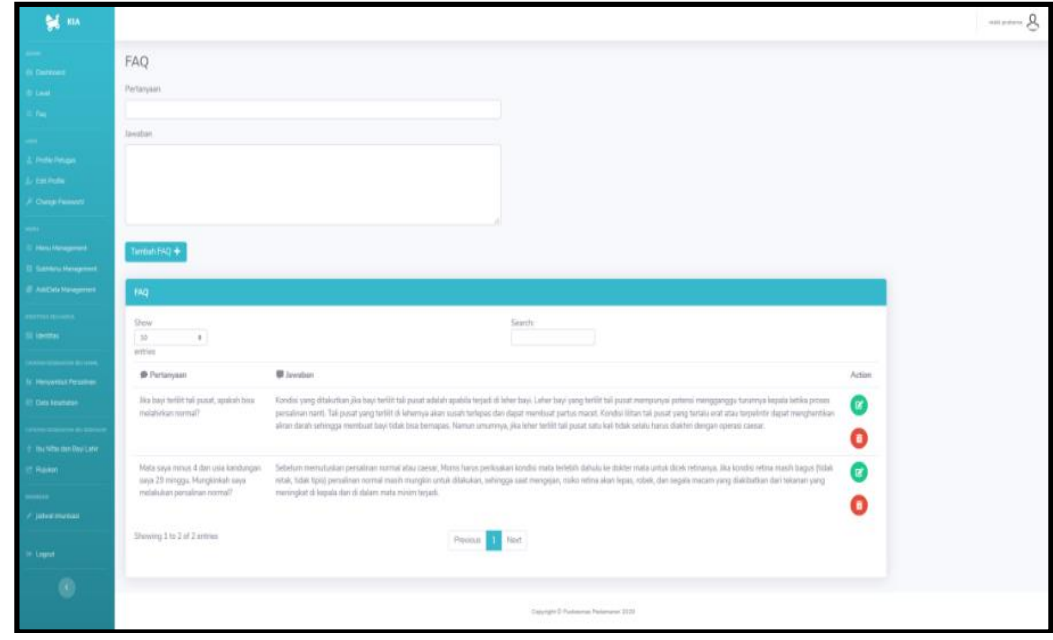

Gambar 4. Halaman FAQ

d. Halaman Identitas

Halaman identitas berfungsi sebagai tempat untuk mengelola data dari ibu hamil yang mendaftar di puskesmas pedamaran.

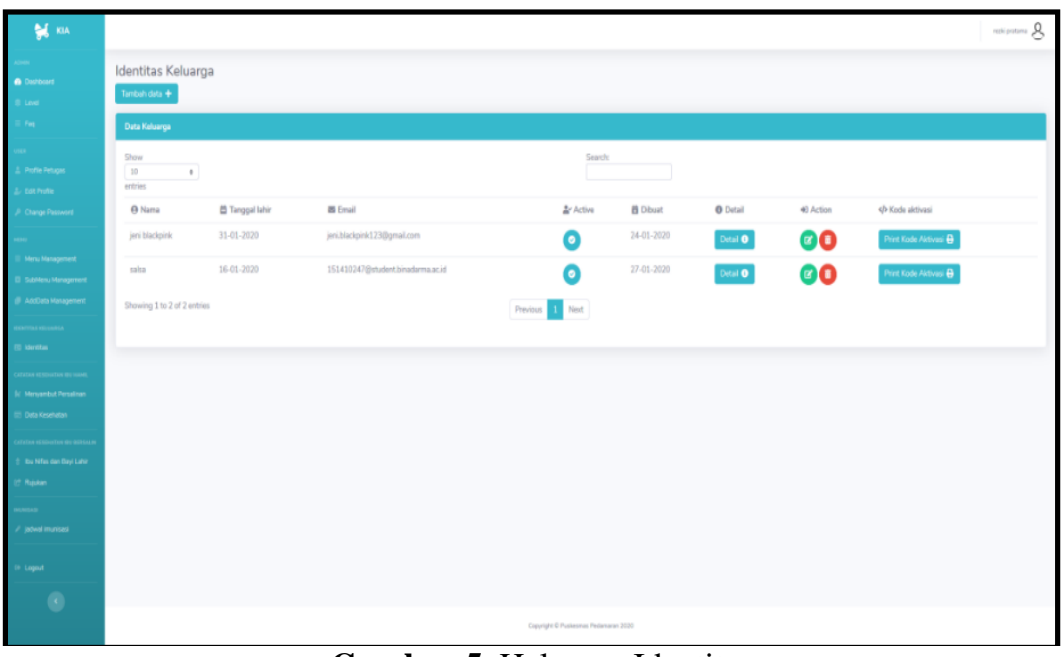

Gambar 5. Halaman Identitas

e. Halaman Data Kesehatan

Halaman data kesehatan berfungsi sebagai tempat untuk mengelola data pemeriksaan kesehatan tiap tiap ibu hamil, pada tampilan ini ibu hamil diharapkan mengisi data anamnesa terlebih dahulu agar dapat mengakses menu riwayat kesehatan. 


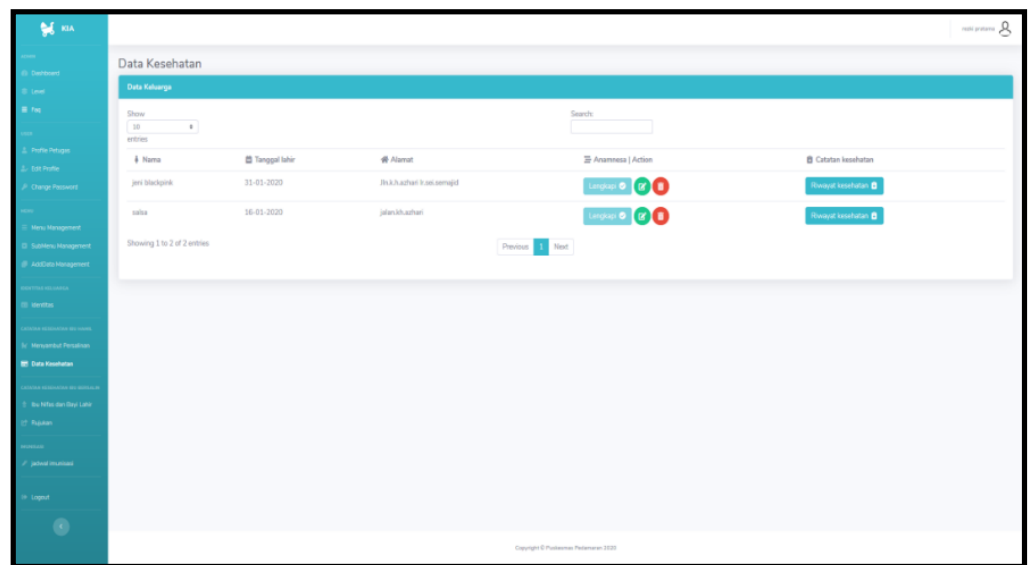

Gambar 6. Halaman Data Kesehatan

f. Halaman Riwayat Kesehatan

Halaman data kesehatan berfungsi sebagai tempat untuk mengelola data pemeriksaan kesehatan tiap tiap ibu hamil, pada tampilan ini ibu hamil diharapkan mengisi data anamnesa terlebih dahulu agar dapat mengakses menu riwayat kesehatan.

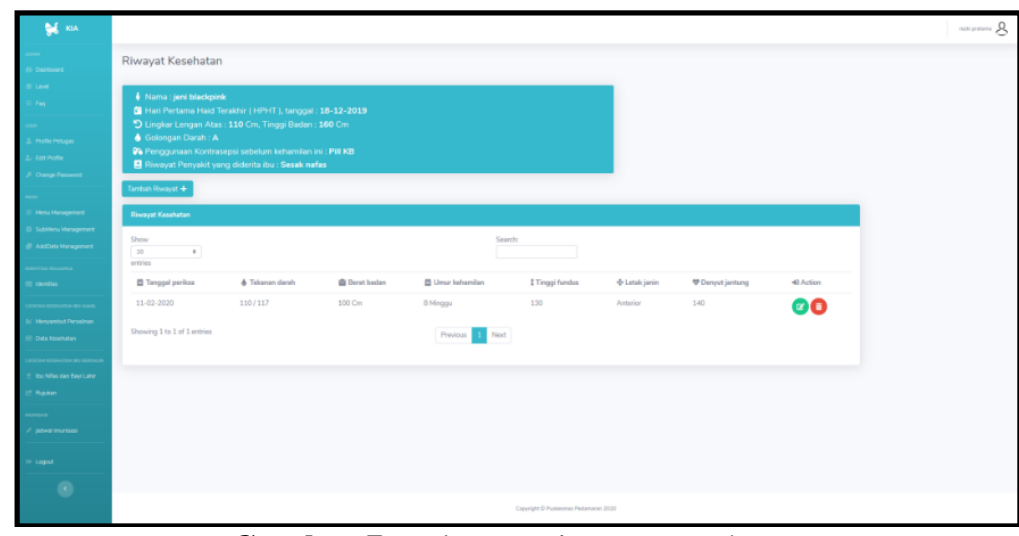

Gambar 7. Halaman Riwayat Kesehatan

g. Halaman Menyambut Persalinan

Halaman menyambut persalinan berfungsi untuk mengelola data ibu hamil yang akan melakukan persalinan di puskesmas pedamaran.

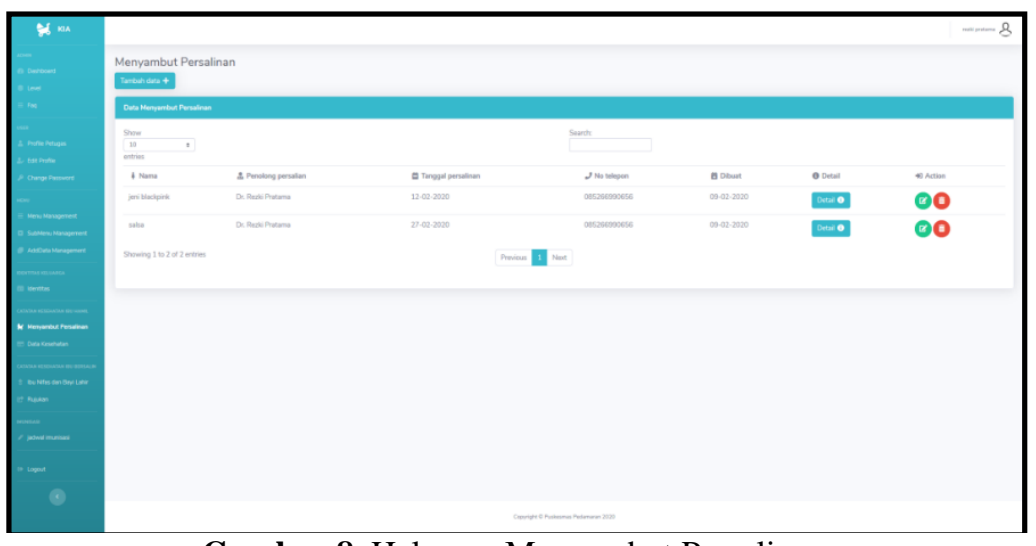

Gambar 8. Halaman Menyambut Persalinan 
h. Halaman Rujukan

Halaman rujukan berfungsi sebagai tempat untuk mengelola data rujukan ibu hamil yang akan merujuk ke fasilitas kesehatan yang lain atau ke rumah sakit.

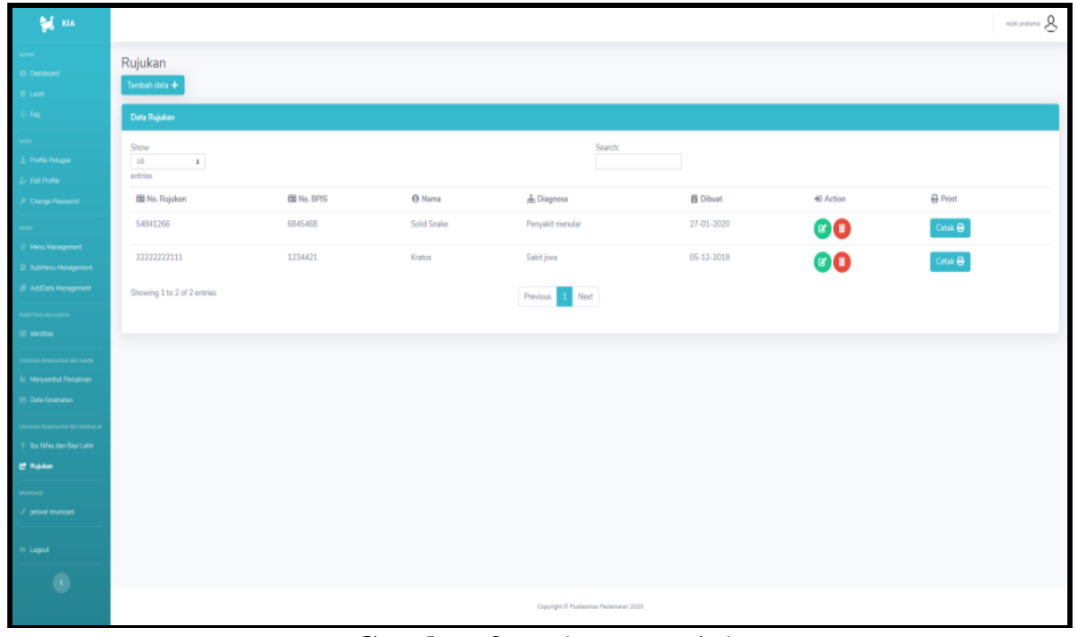

Gambar 9. Halaman Rujukan

i. Halaman Ibu Nifas dan Bayi Lahir

Halaman ibu nifas dan bayi lahir berfungsi sebagai tempat untuk mengelola data ibu yang melahirkan di puskesmas pedamaran.

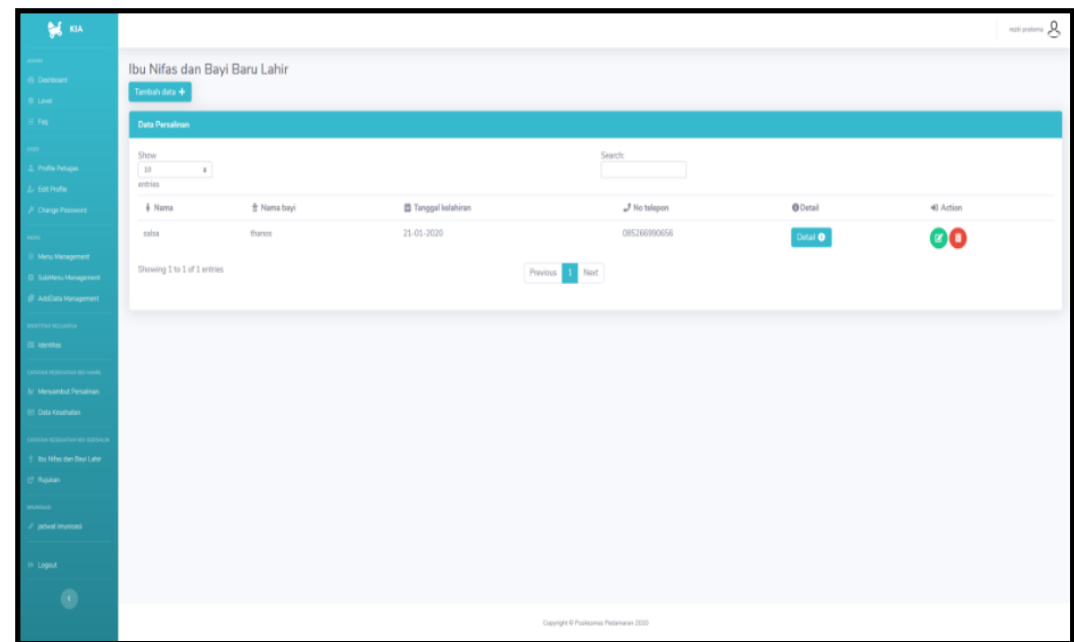

Gambar 10. Halaman Ibu Nifas dan Bayi Lahir

\section{j. Halaman Imunisasi}

Halaman imunisasi berfungsi sebagai tempat untuk mengelola data imunisasi pada tiap -tiap bayi, yang mana digunakan untuk mengakses jadwal imunisasi setiap bayi. 


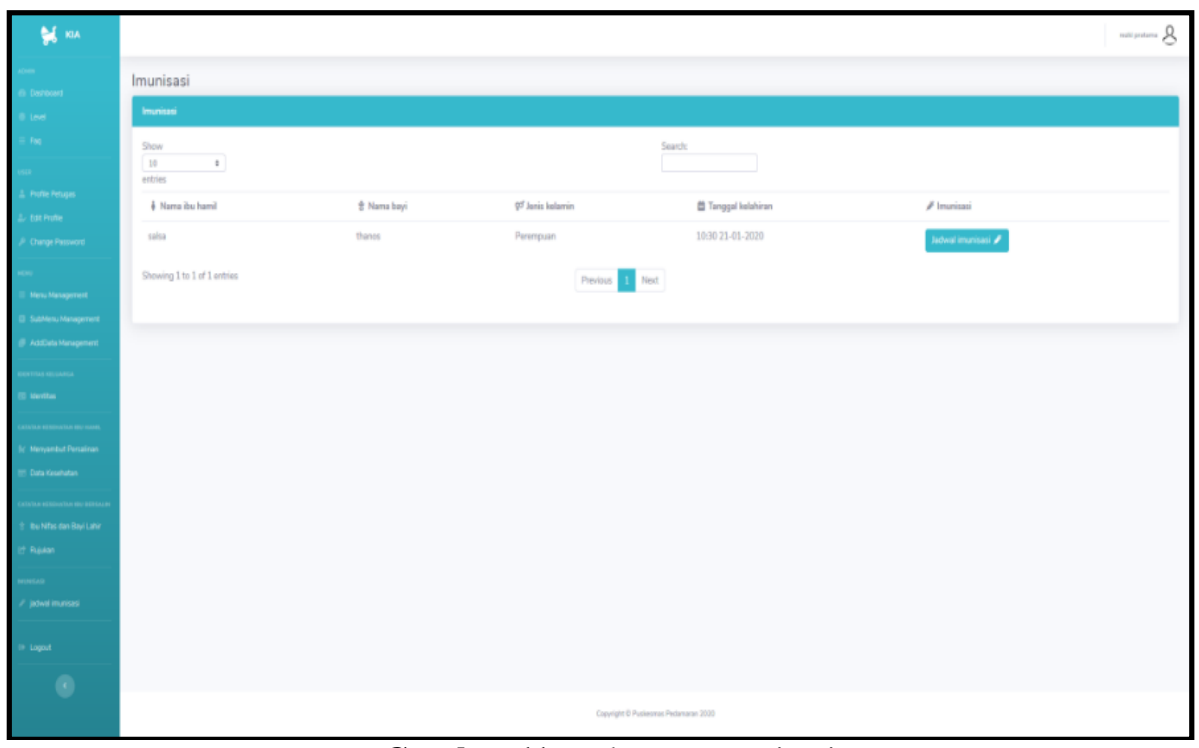

Gambar 11. Halaman Imunisasi

k. Halaman Jadwal Imunisasi

Halaman imunisasi berfungsi sebagai tempat untuk mengelola data imunisasi pada tiap -tiap bayi, yang mana digunakan untuk mengakses jadwal imunisasi setiap bayi.

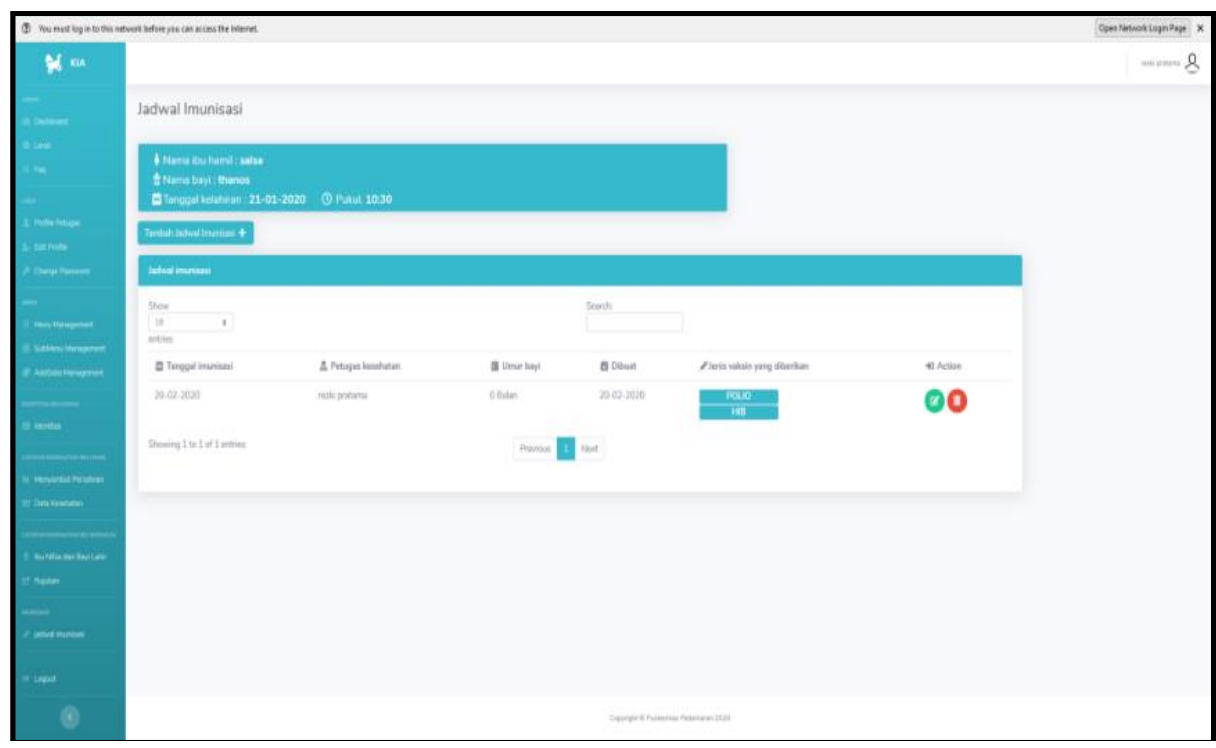

Gambar 12. Halaman Jadwal Imunisasi

\subsection{Tampilan User / Ibu Hamil ( Mobile )}

\section{a. Login Mobile}

Tampilan login berfungsi sebagai tempat untuk ibu hamil masuk ke aplikasi sistem informasi puskesmas kesehatan ibu dan anak untuk melihat informasi kesehatan seputar ibu hamil dan bayi, agar dapat masuk ke aplikasi mobile diperlukan email dan password yang sudah didaftarkan lewat aktivasi akun. 


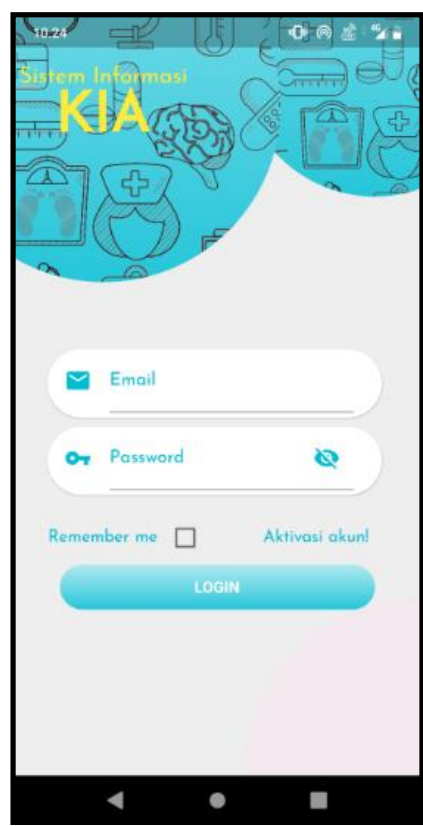

Gambar 13. Login Mobile

b. Aktivasi Akun

Menu aktivasi akun berfungsi sebagai fitur untuk memverifikasi akun yang belum terdaftar dengan menggunakan email dan kode aktivasi, kode aktivasi sendiri didapat lewat email atau meminta langsung kode aktivasi yang telah dicetak oleh petugas kesehatan.

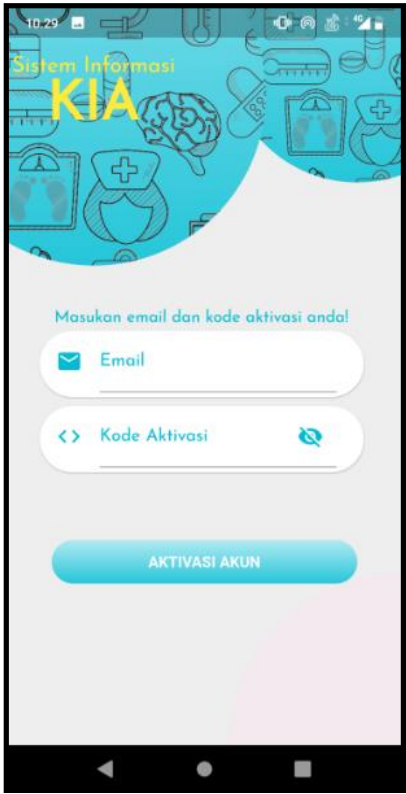

Gambar 14. Aktivasi Akun

c. Home

Pada tampilan tabbar home terdapat beberapa menu yang digunakan untuk mengakses fitur - fitur yang ada di aplikasi, yaitu kelahiran bayi, faq,imunisasi bayi, dan tentang aplikasi. Di tampilan ini juga terdapat umur kehamilan dari ibu yang melahirkan. 


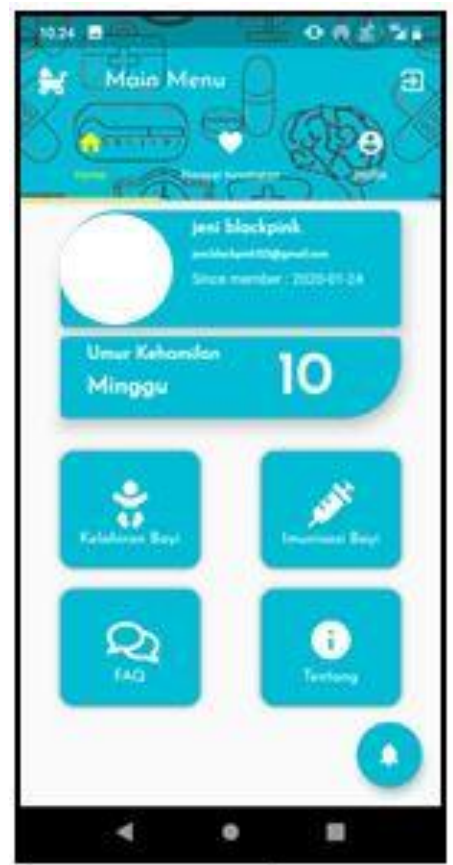

Gambar 15. Home

d. Riwayat Kesehatan

Pada tampilan tabbar riwayat kesehatan terdapat list data hasil dari setiap ibu hamil yang melakukan pemeriksaan kesehatan.

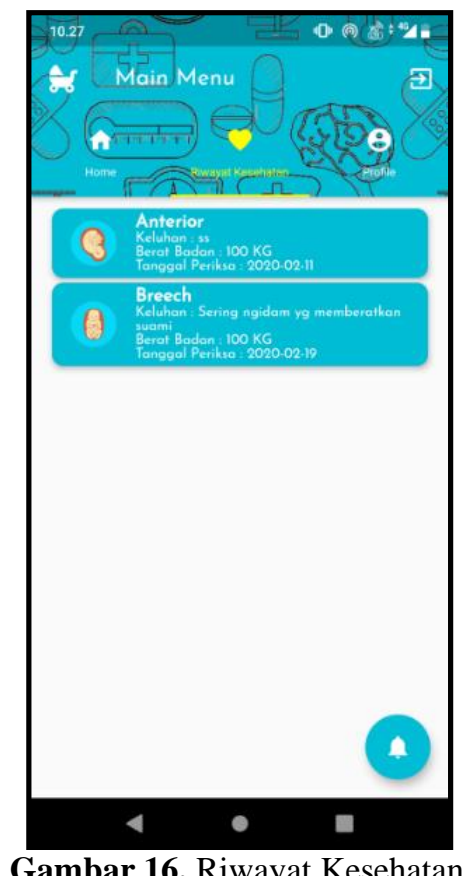

e. Detail Riwayat Kesehatan

Pada detail riwayat kesehatan terdapat beberapa data dari hasil pemeriksaan kesehatan ibu hamil, mulai dari letak janin, keluhan, umur kehamilan, tekanan darah, denyut jantung, fundus, dan berat badan. 


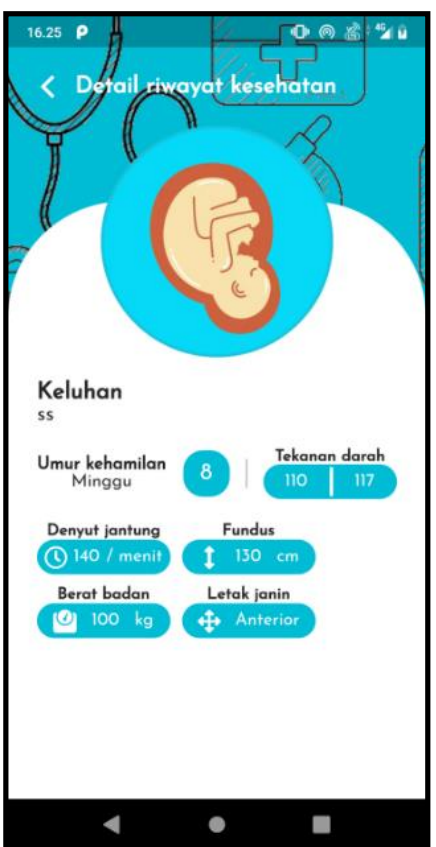

Gambar 17. Detail Riwayat Kesehatan

f. Kelahiran Bayi

Pada menu kelahiran bayi terdapat data bayi dari hasil persalinan di puskesmas pedamaran.

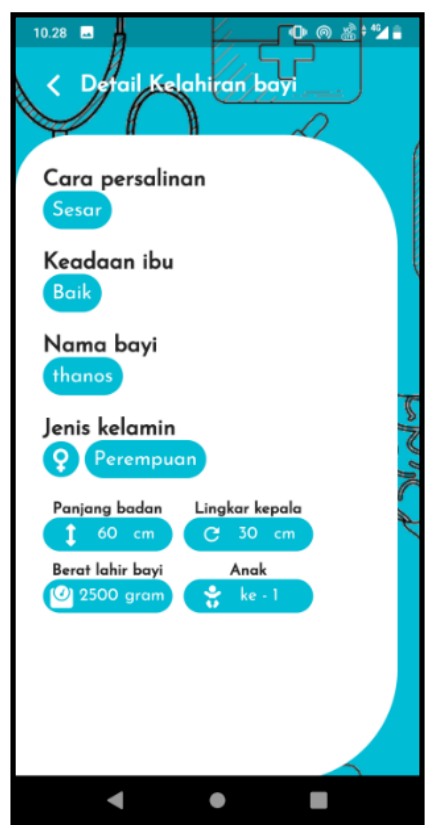

Gambar 18. Kelahiran Bayi

g. FAQ

Pada menu FAQ (Frequently Asked Question) terdapat list pertanyaan dan fitur pencarian dari seputar kesehatan ibu hamil. 


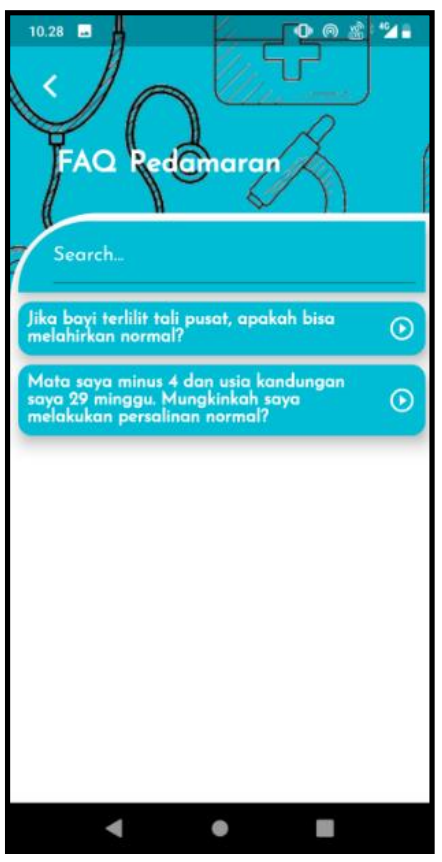

Gambar 19. FAQ

h. Detail FAQ

Pada detail FAQ (Frequently Asked Question) terdapat pertanyaan dan jawaban dari list pertanyaan yang dipilih sebelumnnya.

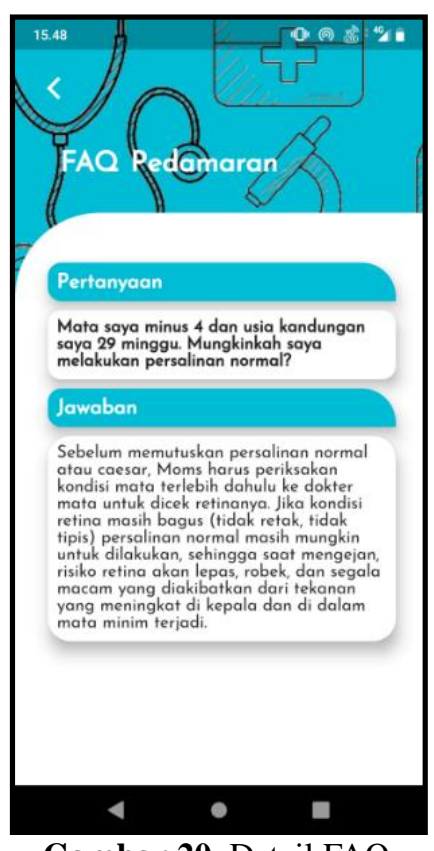

Gambar 20. Detail FAQ

i. Imunisasi Bayi

Pada menu imunisasi bayi terdapat data dari hasil imunisasi yang dilakukan bayi setiap bulannya. 


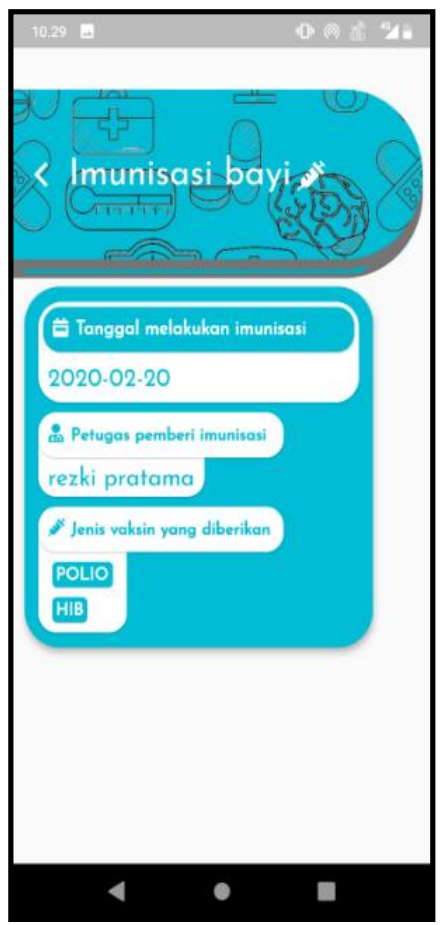

Gambar 21. Imunisasi Bayi

j. Tentang Aplikasi

Pada menu imunisasi bayi terdapat data dari hasil imunisasi yang dilakukan bayi setiap bulannya.

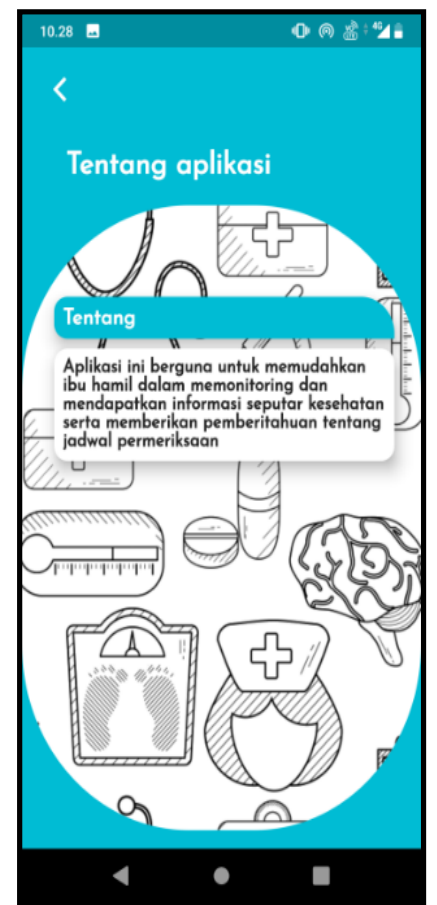

Gambar 22. Tentang Aplikasi 


\section{Kesimpulan}

Setelah menyelesaikan pembahasan serta menjawab dari perumusan masalah, maka penulis mengambil beberapa kesimpulan antara lain:

a. Penggunaan sistem informasi puskesmas yang berbasis web pada sisi admin atau petugas kesehatan sangat membantu dan mempermudah pengolahan data seperti data identitas ibu hamil, data kesehatan, data menyambut persalinan, data rujukan, data ibu nifas dan bayi lahir, dan data imunisasi.

b. Dengan adanya sistem tersebut dapat mengurangi terjadinya penumpukan data dalam pengolahan data ibu hamil dan bayi.

c. Sedangkan pada penggunaan aplikasi mobile pada sisi user atau ibu hamil sangat membantu dalam memberikan informasi seputar kesehatan ibu maupun bayi dan dapat memberikan notifikasi secara berkala sebagai pengingat jadwal pemeriksaan kesehatan ataupun imunisasi.

\section{Daftar Pustaka}

[1] N. Y. Fitri and N. Nurhadi, "Analisis Dan Perancangan Sistem Pendukung Keputusan Penilaian Kinerja Guru Dengan Menggunakan Metode Simple Additive Weighting (Saw) Pada Smk Yadika Jambi," Jurnal Manajemen Sistem Informasi, vol. 2, no. 1, pp. 318-326, 2017.

[2] F. Rahman and S. Santoso, "Aplikasi Pemesanan Undangan Online," Jurnal Sains dan Informatika, vol. 1, no. 2, 2017.

[3] F. Fatmawati, "Perancangan sistem informasi pemesanan katering berbasis web pada rumah makan Tosuka Tangerang," Jurnal Teknik Komputer, vol. 2, no. 2, pp. 33-41, 2016.

[4] L. A. Garing, S. C. Takarendehang, and A. Kamal, "SISTEM PENDUKUNG KEPUTUSAN KELAYAKAN AKREDITASI PUSKESMAS DENGAN METODE ANALYTIC HIERARCHY PROCESS (AHP) PADA DINAS KESEHATAN KABUPATEN SANGIHE," Jurnal Ilmiah Behongang, vol. 1, no. 1, pp. 16-21, 2018.

[5] A. N. Ananda, "Mobile Commerce Berbasis Android Pada PT. Mega Mulia Pharma Palembang," PhD Thesis, POLITEKNIK NEGERI SRIWIJAYA, 2018.

[6] B. Paramita, L. A. Abdillah, and E. S. Negara, "ANALISIS MONITORING TRAFFIC JARINGAN PADA PT KAI DIVISI REGIONAL III SUMSEL,” p. 6, 2016.

[7] Rahman, F., 2015. Aplikasi Pemesanan Undangan Online. J. Sains Dan Inform. 1, 10.

[8] Rosa A. S, Salahudin, M., 2018. REKAYASA PERANGKAT LUNAK TERSTRUKTUR DAN BERORIENTASI OBJEK. Informatika Bandung. 